\title{
The gene suicide system NTR/CB1954 causes ablation of differentiated 3T3L1 adipocytes by apoptosis
}

\author{
RICARDO N FELMER ${ }^{1}$ and JOHN A CLARK
}

Department of Gene Expression and Development, Roslin Institute, Roslin, Midlothian, EH25 9PS, Scotland, UK.

${ }^{1}$ Present address: Biotechnology Unit, INIA CRI-Carillanca, Temuco, Chile

\begin{abstract}
The feasibility of ablating differentiated adipocytes and the mechanism of cell ablation with a suitable prodrug activating system is described. The system is based on the use of E. coli nitroreductase (NTR) enzyme that activates certain nitro compounds, such as the antitumor drug CB1954, into cytotoxic DNA interstrand cross-linking agents. Differentiated preadipocyte cells (3T3L1) transfected with an aP2 driven nitroreductase construct were efficiently killed after incubation with medium containing the prodrug CB1954, while untransfected cells were not affected. It was demonstrated that the mechanism of cell ablation is apoptosis and that the system has a bystander effect mediated by a toxic metabolite of the prodrug. The described system should provide a good alternative approach for gene therapy studies and a new inducible approach to manipulating the number of cells in tissues of transgenic animals and the ability to study the recovery of the tissue from cell damage or loss.
\end{abstract}

Key terms: genetic ablation, NTR/CB1954, adipocytes, differentiation

\section{INTRODUCTION}

Genetic ablation is a powerful tool that allows the removal of specific cell types by targeting expression of intracellular toxins (Breitman et al., 1987). This approach provides a means of generating mutant animals lacking a particular cell type or an entire cell lineage. These animals become important models for studying the role that specific cell types play in physiological processes and cell fate during embryogenesis (Palmiter et al., 1987; Evans, 1989; Camper et al., 1995). As a corollary of this technology, 'suicide gene therapy' emerged as an approach aimed at enhancing the selectivity of cancer chemotherapy of solid tumors. In this approach, the expression of a toxic gene or a gene whose product can convert an otherwise harmless prodrug into a cytotoxic species is targeted to specific cell types by using the appropriate regulatory sequences. The latter approach known as gene-directed enzyme prodrug therapy (GDEPT) (Brigewater et al., 1995) or virusdirected enzyme prodrug therapy (VDEPT) has the potential of creating a much higher concentration of the active cytotoxic drug within the microenvironment of the tumor that can be achieved by systemic administration of the active drug itself. In the past decade, most of the attention with respect to anti-cancer applications (Moolten et al., 1990; Izquierdo et al., 1996) and targeted cell ablation in transgenic mice (Borrelli et al., 1989; Wallace et al., 1991) was directed toward the herpes simplex thymidine kinase (HSV-tk). In fact, many clinical trials have already taken place with the enzyme-prodrug combination HSVtk/ganciclovir (Springer and Niculescu-Duvaz 2000). Thymidine kinase converts ganciclovir to a number of toxic metabolites that end up inhibiting DNA polymerase, hence it is assumed to be active only in proliferating cells, which leaves differentiated cells refractory to this system. 
Here we describe the potential use of another system for cell ablation that may overcome some of the limitations normally encountered with some gene suicide systems. This system is based on the use of the E. coli nitroreductase (NTR) enzyme that activates certain nitro-compounds, such as the antitumor drug CB1954, into potent cytotoxic agents capable of DNA cross-linking (Knox et al., 1993). This system has demonstrated the feasibility of ablating both dividing and non-dividing cells (Clark et al., 1997; Drabek et al., 1997; Isles et al., 2001), and we have recently demonstrated the inducible ablation of adipocytes in adult transgenic mice (Felmer et al., 2002). In order to get a better understanding of the mechanism of NTR/ CB1954 mediated ablation in adipocytes, 3T3L1 preadipocyte cell lines were stably transfected with a construct containing the $E$. coli nitroreductase gene driven by the adipocyte specific promoter aP2 (Ross et al., 1990). After differentiation, a number of clones stably expressing the nitroreductase enzyme could be efficiently killed by the administration of the prodrug to the culture medium, confirming the ability of this system to kill differentiated adipocytes. It was demonstrated that the mechanism of adipocyte killing was apoptosis and a bystander effect, which is presumably mediated by toxic metabolites of CB1954, could be observed.

\section{MATERIALS AND METHODS}

\section{Plasmid construction}

A $1.55 \mathrm{~kb}$ fragment containing the E. coli $n t r$ gene and the poly A signal from SV40 was liberated from the plasmid pWR6, kindly provided by Dr. W. Cui (Clark et al., 1997), by double digestion Hind III/Xba I and end filled ligated into the unique Sma I site of the aP2 promoter/enhancer plasmid (kindly provided by Dr. R. Graves (Ross et al., 1990) to generate the aP2-NTR plasmid. Then a $1.8 \mathrm{~kb}$ fragment containing the NEO cassette, kindly provided by Dr. E. Gallagher (Gallagher et al., 2003), was excised with Xho I and ligated into the aP2NTR plasmid and digested with Xho I to generate the NTR-NEO plasmid used for transfection experiments.

\section{Cell culture and transfection experiments}

Culture and differentiation of mouse embryo 3T3L1 preadipocytes (American Type Culture Collection) was performed as described previously (Student et al., 1980). Briefly, cells were propagated to confluence in medium DMEM with $10 \%$ FCS. On differentiation day 0 , cells were fed with DMEM supplemented with $10 \%$ FCS, 0.5 $\mathrm{mM}$ methylisobutylxanthine, $10 \mu \mathrm{g} / \mathrm{ml}$ of insulin, and $1 \mu \mathrm{M}$ dexamethasone. Cells were changed to culture medium lacking methylisobutylxanthine and dexamethasone 2 days later (differentiation day 2) and cultured in this medium for 6 days. Cells were stably transfected by calcium phosphate with a construct containing the E. coli nitroreductase gene driven by the adipocyte specific promoter aP2 (Ross et al., 1990). Isolation of independent clones was carried out by ring cloning after selection for 10 days in medium containing $400 \mu \mathrm{g} / \mathrm{ml}$ of G418.

\section{Prodrug preparation}

CB1954 was dissolved initially in dimethylsulfoxide (DMSO) at a concentration of $25 \mathrm{mg} / \mathrm{ml}$ and subsequently into media. Stably transfected and parental 3T3L1 cells, after differentiation into adipocytes, were incubated with media containing the prodrug CB1954 at different concentrations.

\section{DNA fragmentation assay}

Cells were harvested by centrifugation and the pellet lysed with $0.4 \mathrm{ml}$ hypotonic lysing buffer (10 mM Tris, $1 \mathrm{mM}$ EDTA, $\mathrm{pH} 7.5)$ containing $0.2 \%$ Triton-X 100, as described by Sellins and Cohen (1987). Lysates were centrifuged at $13,000 \times \mathrm{G}$ for 10 minutes to separate intact from fragmented chromatin. The supernatant fraction containing fragmented DNA was placed in a separate tube, which was then precipitated overnight at $-20^{\circ} \mathrm{C}$ in $50 \%$ isopropanol and $0.5 \mathrm{M}$ $\mathrm{NaCl}$. The precipitate was pelleted by centrifugation, air-dried, and suspended in an appropriate volume of TE. The pellet 
consisting of cells was digested overnight with $0.5 \mathrm{ml}$ digestion buffer $(100 \mathrm{mM}$ Tris$\mathrm{HCl} \mathrm{pH} 8.5,5 \mathrm{mM}$ EDTA pH 8.0, $200 \mathrm{mM}$ $\mathrm{NaCl}, 0.2 \%$ SDS and fresh $100 \mu \mathrm{g}$ Proteinase $\mathrm{K} / \mathrm{ml}$ ) in a shaking incubator at $55^{\circ} \mathrm{C}$. It was then centrifuged and the supernatant decanted into $0.5 \mathrm{ml}$ of isopropanol and finally the genomic DNA suspended in appropriate volume of TE.

\section{Apoptosis (Tunel) staining}

Apoptosis was detected using the peroxidase apoTag kit (Appligene Oncor). Fixed cells were pretreated with proteinase $\mathrm{K}(20 \mu \mathrm{g} / \mathrm{ml})$ for 15 minutes at RT. Endogenous peroxidase was blocked with $3 \%(\mathrm{v} / \mathrm{v})$ hydrogen peroxide for 5 minutes at RT. Samples were incubated with TdT enzyme in a humidified chamber at $37^{\circ} \mathrm{C}$ for 1 hour. Anti-digoxigenin peroxidase conjugate was applied directly to the slides and incubated in a humidified chamber for 30 minutes at RT. The color was developed by incubation with a $\mathrm{DAB} / \mathrm{H}_{2} \mathrm{O}_{2}$ solution for 10 minutes. Sections were counterstained with methyl green, mounted in DPX, and visualized by light microscopy.

\section{RESULTS}

Transfection of preadipocytes $3 T 3 L 1$ cells and expression assays

A number of independent clones were induced to differentiate with hormonal agents as described in the Material and Methods section. Prior to differentiation, these cells were morphologically similar to fibroblastic preadipose cells in the stroma of the adipose tissue (Fig. 1A). At day 5 of differentiation, many cytoplasmic triacylglycerol-containing vacuoles begun to appear (Fig. 1D) which, after an extended period in culture, coalesced to form unilocular fat droplets (Fig. 1F). All transfected cells treated in this way differentiated normally and showed no difference from the control (parental cells), indicating that the E. coli sequences did not affect the normal survival of these cells nor their ability to differentiate into adipocytes.
Subconfluent
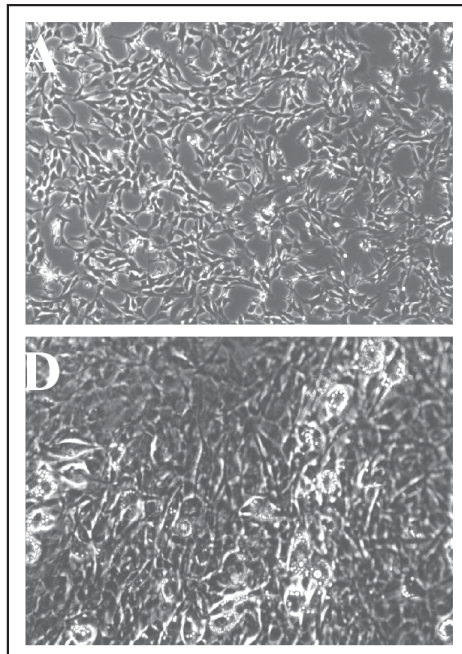

5 Days
Confluent
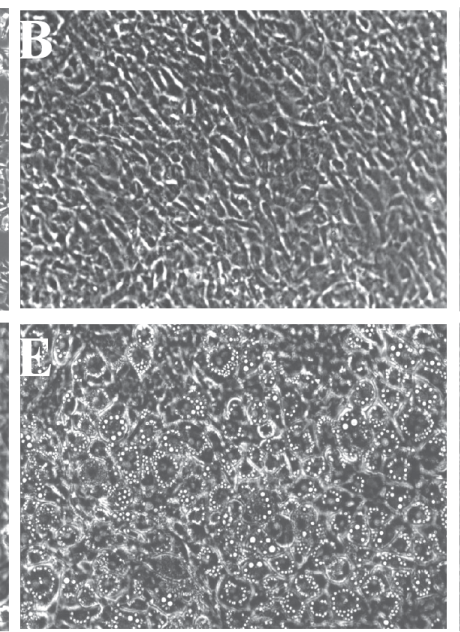

7 Days
3 Days

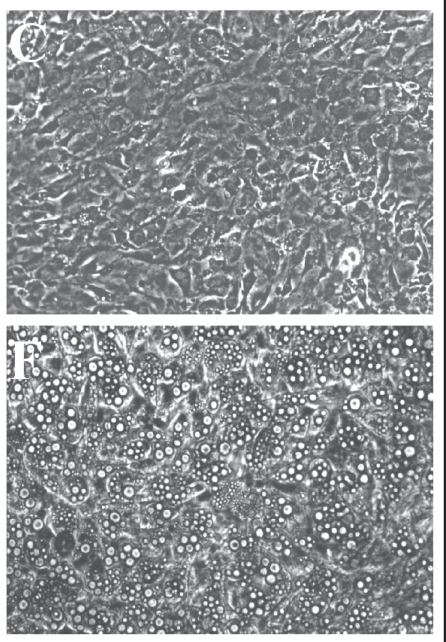

10 Days

Figure 1. Adipocyte Differentiation in vitro. Phase-contrast photomicrograph of transfected preadipocyte cell lines at different stages of differentiation (A, B, C, D, E, and F, respectively). Cells were induced to differentiate after confluence (panel B) with a cocktail of hormones/steroids, as described in Material and Methods section. Normal differentiation of these cells is observed throughout the differentiation process as evidenced by the lipid accumulation in the cytosol of the cells (panel F). Original Magnification 100X. 
Expression analysis of differentiated adipocytes showed relatively high levels of nitroreductase expression in two out of seven clones (Fig. 2A, clones A and 10, respectively). The other clones also expressed nitroreductase although in some cases they were detectable only by the more sensitive RTPCR technique (data not shown). The developmental regulation of nitroreductase expression from the aP2 promoter was analyzed during the differentiation process. The adipocyte $\mathrm{P} 2(\mathrm{aP} 2)$ is a very abundant adipocyte-specific member of the large family of intracellular lipid carrier proteins (Cook et al., 1988). The gene for adipocyte $\mathrm{P} 2$ has been used as a model for understanding gene regulation in this cell type and its expression is confined to differentiated adipocytes (Ross et al., 1990). The regulation of nitroreductase expression was studied in clone 10 , for which RNA was collected at different time points including before differentiation $(\mathrm{P})$ and at 3, 5, 8, and 11 days after hormonal induction (Fig. 2B). In this clone, both the endogenous aP2 and the aP2 driven nitroreductase mRNAs increased with a similar time course during differentiation and reached a plateau at the same time. As expected, both mRNA species were undetectable prior to the differentiation of the cells, thus confirming previous observations of this promoter being active only in differentiated cells (Ross et al., 1990).

\section{NTR/CB1954 mediated ablation of differentiated $3 T 3 \mathrm{~L} 1$ cells}

In order to assess the survival rate of these cells to the prodrug CB1954, differentiated cells stably expressing nitroreductase and the parental cell lines, were grown with medium containing different concentrations of the prodrug. The effects on the cells grown in medium containing $100 \mu \mathrm{M}$ of CB1954 is shown in Figure 3. Only transfected cells showed signs of cytoxicity, such as cell shrinkage and membrane blebbing, that was evident under these conditions after 3 days. After 6 days, most of the cells have disappeared from the dish, an irreversible effect, since returning the cells to prodrug free medium did not lead to their recovery (data not shown). On the other hand, parental cells were not affected by this concentration of the prodrug even after longer time exposure to the culture medium. The first signs of toxicity in these cells were observed only when the concentration of the prodrug was increased up to $2.5 \mathrm{mM}$ (Fig. 4 ), giving rise to a calculated therapeutic index of approximately $25\left(\mathrm{LD}_{50}\right)$.

Nitroreductase expression correlated positively with the sensitivity of transfected cells to the prodrug. Parental cells and clones 3, 10 and $\mathrm{A}$, all expressing nitroreductase at different levels (Fig. 2A), were grown with medium containing the prodrug at a concentration of $100 \mu \mathrm{M}$ and the number of surviving cells counted at different time points. Clones of cells expressing lower levels of nitroreductase were more resistant to the prodrug than those expressing higher levels (Fig. 5) thus suggesting that the sensitivity is correlated to the nitroreductase enzyme available to metabolise the prodrug.

\section{The mechanism of NTR/CB1954 mediated ablation of adipocytes is apoptosis}

Apoptosis or programmed cell death represents a physiological form of cell death that occurs during development and in the mature animal. Activation of CB1954 by the E. coli nitroreductase, results on DNA interstrand cross-linking, which is though to induce this endogenous self-destructive response (Friedlos et al., 1992; Knox et al., 1993). Considering that the cleavage of genomic DNA into oligonucleosome-length fragments represents a biochemical mark of apoptosis (Bortner et al., 1995), a DNA fragmentation assay was carried out in nitroreductase expressing and parental cells grown in medium containing the prodrug and in prodrug-free medium. Figure $6 \mathrm{~A}$ shows a characteristic DNA laddering only in cells expressing nitroreductase and treated with the prodrug. This pattern was not observed in the control cells, nor was it observed in the nitroreductase-expressing cells grown in prodrug-free medium. This data was further confirmed by a Tunel assay carried out in fixed cells. This assay showed specific staining indicative of apoptosis mediated DNA strand breaks only in nitroreductase-expressing cells treated with the prodrug, while no staining could be observed in the control cells (Fig. 6B ii). 
A)

\section{$\begin{array}{llllllll}\mathrm{A} & \mathrm{C} & 2 & 3 & 4 & 7 & 10 & -\end{array}$}

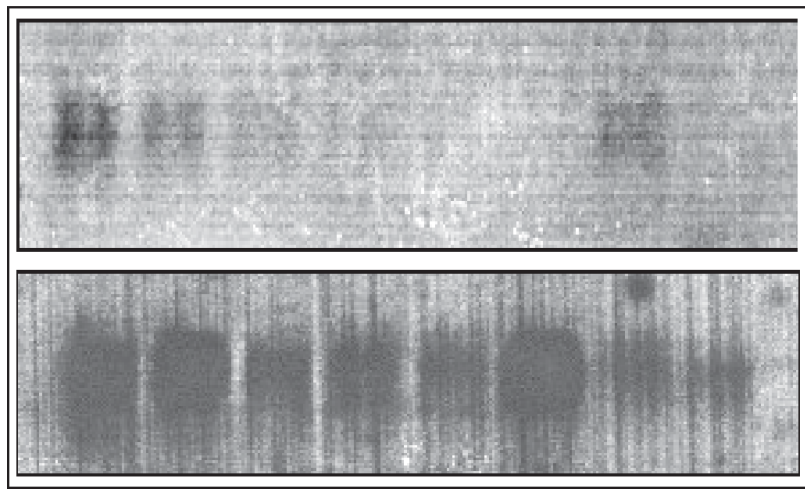

NTR

GAPDH

B)

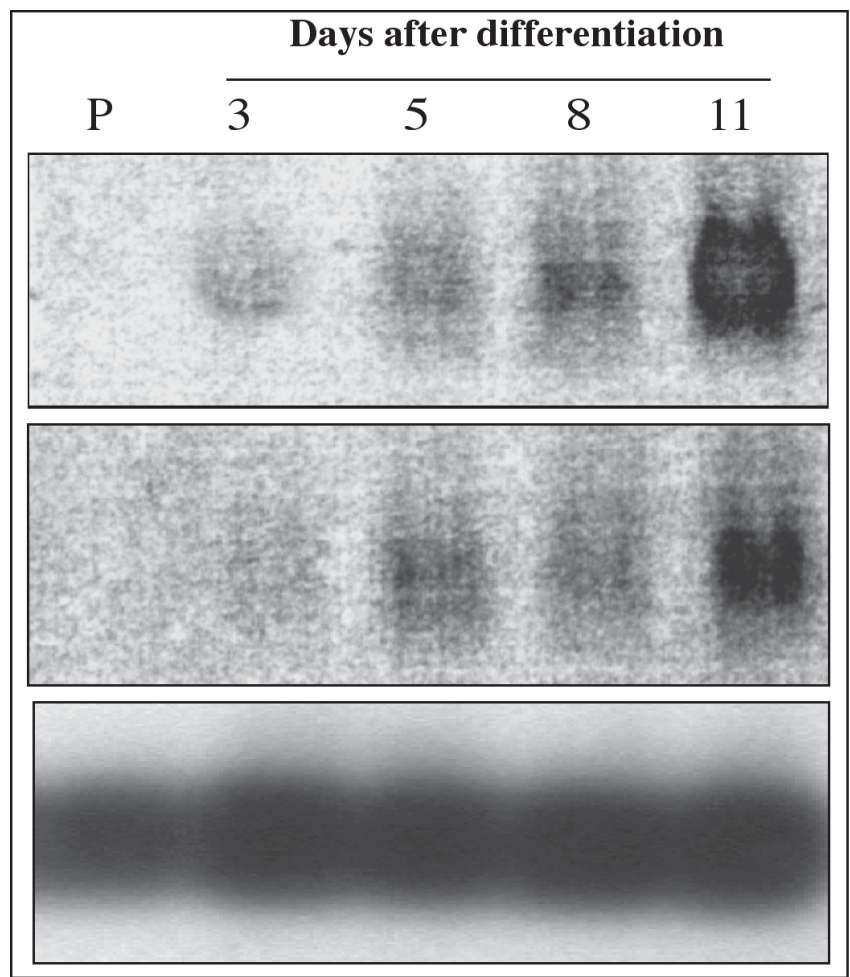

$\mathrm{aP2}$

NTR

\section{GAPDH}

Figure 2. RNA expression assays.

A) NTR expression in transfected 3T3L1 cells. $10 \mu \mathrm{g}$ of total RNA was extracted from individual clones (clones A, C, 2, 3, 4, 7, and 10) and run on a denaturing agarose gel and Northern blot hybridized with a nitroreductase probe to detect the transgene (upper panel) and with a GAPDH probe as a loading control (lower panel). Nitroreductase expression is observed in most of the clones A, C, 2, 3 and 10, respectively.

-: Negative control, RNA from parental cell line.

B) Time course appearance of both the endogenous aP2 and the aP2 driven NTR transcripts in transfected cells.

Total RNA was collected at different time points of the differentiation protocol (as indicated in the figure) and Northern blot hybridized with probes to detect both the endogenous aP2 and the aP2 driven NTR transcripts. GAPDH probe was used as a loading control. NTR transgene shows a developmental pattern of expression similar to the endogenous aP2.

P: Preadipocytes (before differentiation).

$3,5,8$, and 11: Correspond to days after induction of differentiation. 


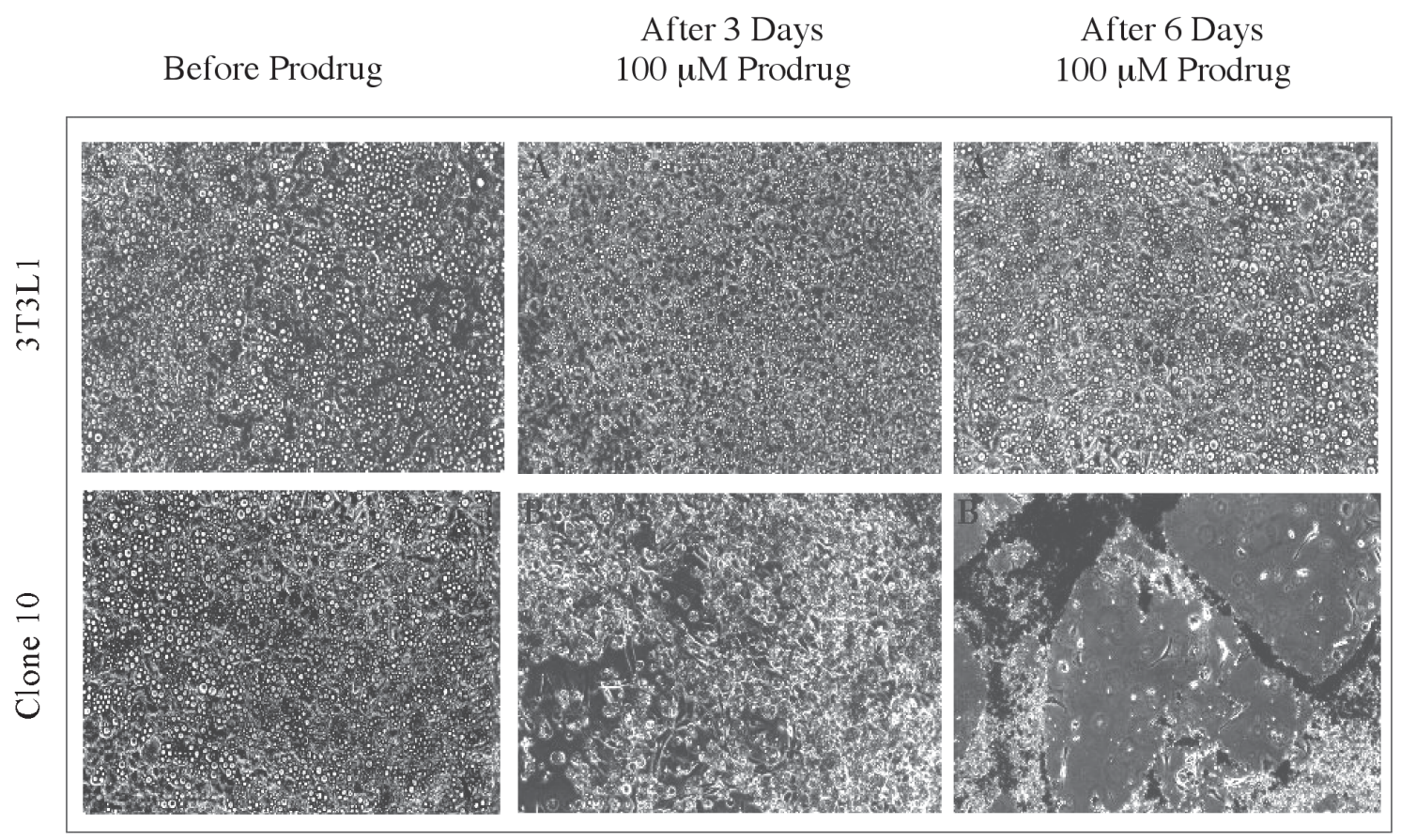

Figure 3. Effect of CB1954 in adipocytes stably expressing NTR (clone 10) and parental 3T3L1 cells.

Phase-contrast photomicrograph of cells incubated in medium containing CB1954. $100 \mu \mathrm{M}$ of prodrug treatment does not produce toxic effect in parental 3T3L1 cells, even after 6 days of treatment. In contrast, transfected cells show signs of citoxicity as soon as day 3 after treatment. After 6 days, most of the cells have disappeared from the dish.

Original magnification 100X except middle panel 40X.

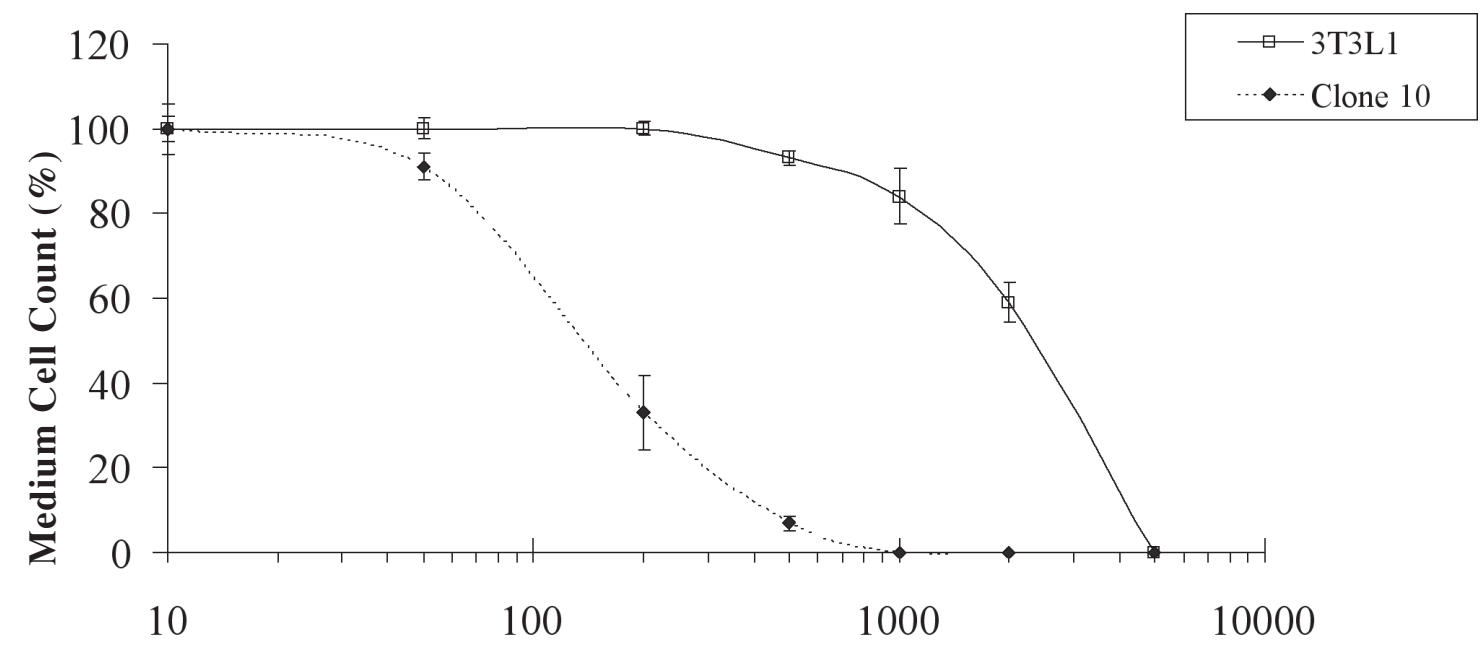

CB1954 $\mu_{M}$

Figure 4. Dose-dependence of in vitro cytotoxicity in adipocytes with the prodrug CB1954.

Nitroreductase expressing cells (clone 10) and parental cell lines (3T3L1) were incubated with increasing concentrations of CB1954 and the number of surviving cells counted after 72 hours. Each point represents the mean \pm s.d. of duplicates. $X$ axis is logarithmic. Open and closed symbols represent the data obtained with parental and transfected cells, respectively. 


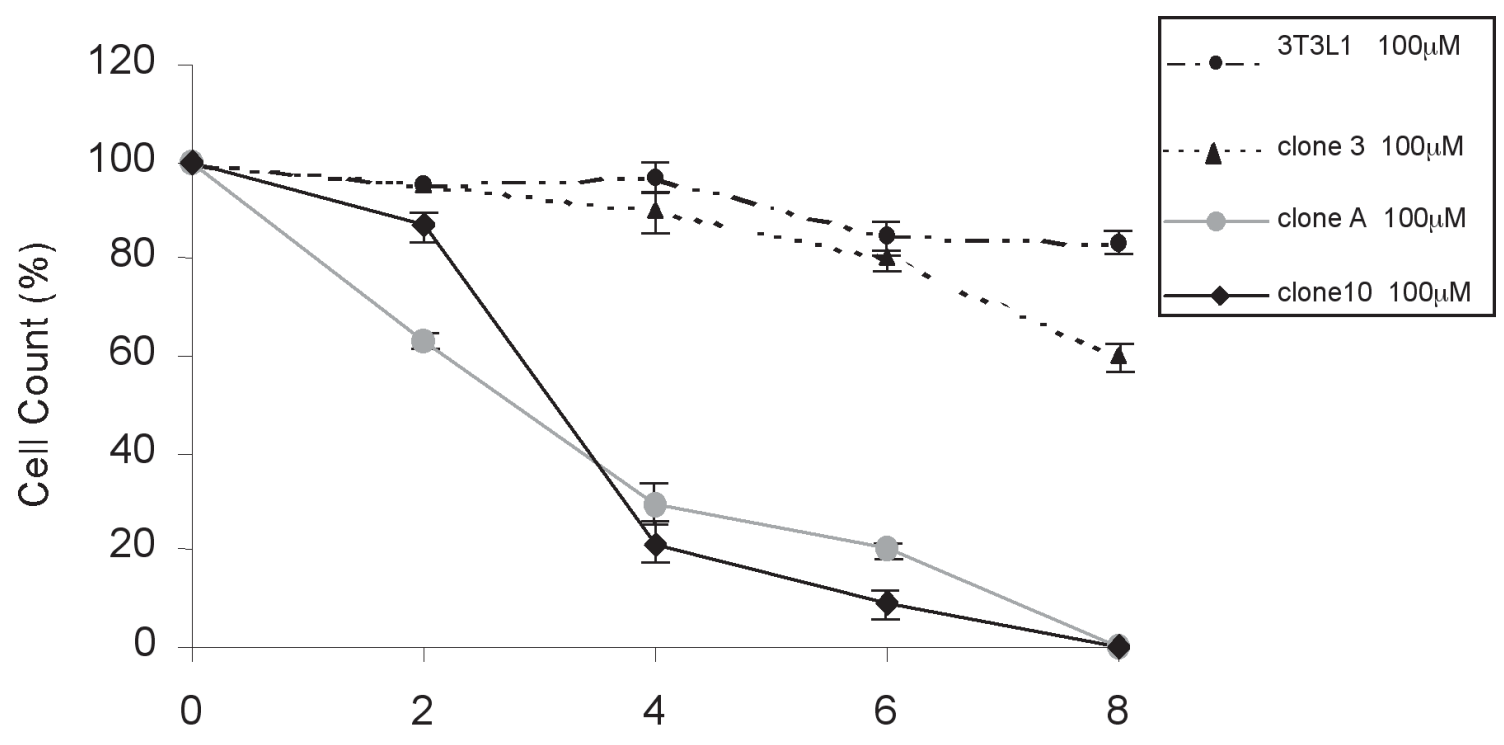

Days

Figure 5. Degree of toxicity correlates to the levels of NTR expression.

Parental and transfected cells expressing different levels of the NTR enzyme were incubated in medium containing $100 \mu \mathrm{M}$ of CB1954 and the number of cells determined at different time points. Each point represents the mean \pm s.d. of duplicates.

NTR/CB1954 has a bystander effect mediated through a toxic metabolite

In order to demonstrate the possible involvement of a toxic metabolite of CB1954 in the bystander effect, nitroreductase-expressing and nonexpressing (parental) cells were cultured with media alone or with media containing CB1954. Conditioned medium (CMED) was collected from each of these cultures after 96 hours, filtered with $0.2 \mu \mathrm{m}$ filters, and transferred to parental 3T3L1 cells. Cell survival of parental cells was measured after another 96 hours of culture. CMED from clones expressing nitroreductase (clone 10) treated with CB1954 reduced cell survival to $50 \%$ as measured by cell counting and observed by light microscopy (Fig. 7D). In contrast, CMED from transfected cells without CB1954 treatment or from parental cells with or without CB1954, showed no signs of toxicity nor a reduction in the number cells (Fig. 7A, B and $\mathrm{C}$, respectively). This data confirmed the presence of an active metabolite of
CB1954 that passed into the CMED and that was sufficiently stable to confer cytotoxicity following transfer.

\section{DISCUSSION}

We recently described the inducible ablation of adipocytes with NTR/CB1954 system in transgenic mice (Felmer et al., 2002). After treatment with the prodrug, transgenic mice showed extensive cell depletion in all fat depots, which was directly correlated to both the dose of the prodrug and the levels of NTR expression. Interestingly, we observed complete disappearance of some adipose depots, suggesting a bystander effect, since immnuohistochemical analysis of these mice showed a variegated pattern of transgene expression, which contrasts with studies on the ablation of mammary epithelial cells where this bystander effect was not observed (Clark et al., 1997). Therefore, in order to better understand the mechanism of adipocyte ablation and the 
bystander effect of this gene suicide system, an in vitro assay using the preadipocyte cell line 3T3L1 was developed. 3T3L1 cells were stably transfected with the $E$. coli nitroreductase gene driven by the adipocyte specific promoter aP2 (Ross et al., 1990).
Transfected preadipocyte cells showed normal differentiation into adipocytes indicating that $E$. coli nitroreductase is not detrimental for the survival of the cells or for an appropriate differentiation into adipocytes.

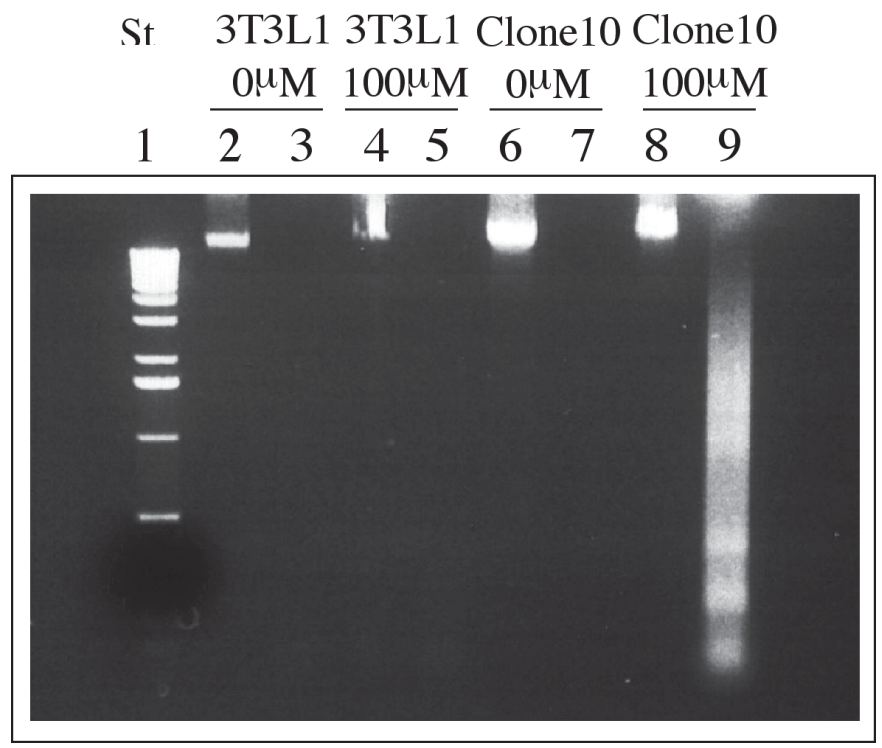

3T3L1 CB1954

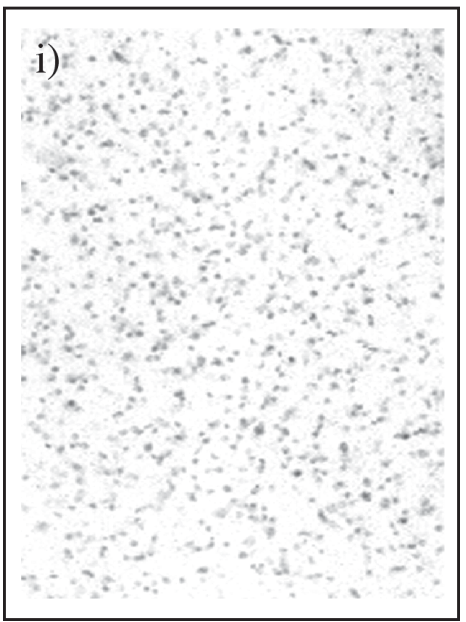

Clone 10 CB1954

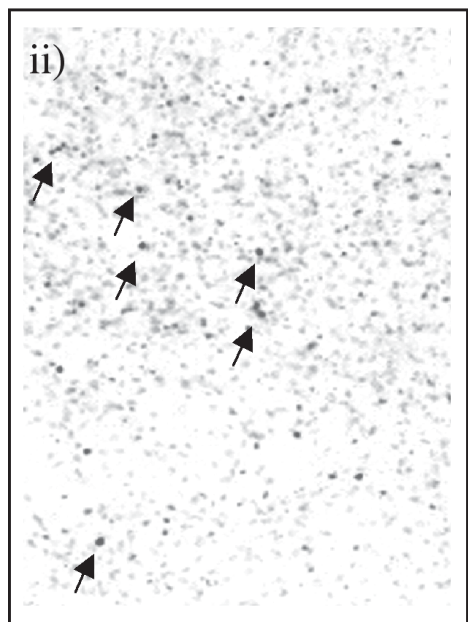

Figure 6. Apoptosis Assays.

A) DNA Fragmentation assay. Genomic DNA was prepared from cells (lanes 2, 4, 6, and 8, respectively) and the supernatant fraction (lanes 3, 5, 7, and 9, respectively) according to the method described in Material and Methods section. Cells were treated with $100 \mu \mathrm{M}$ of CB1954 for 4 days and then analyzed. A DNA laddering, characteristic of apoptotic cells was observed only in the supernatant fraction of cells expressing NTR treated with the prodrug (lane 9).

B) Tunel assay. The assay was carried out in fixed cells (clone 10 and parental 3T3L1) treated for two days with $100 \mu \mathrm{M}$ of CB1954. A characteristic brown color staining indicative of apoptotic nuclei is observed only in cells expressing NTR (arrows in panel ii).

Original magnification 200X. 


\section{T3L1 CMED 3T3L1 CMED + CB1954}

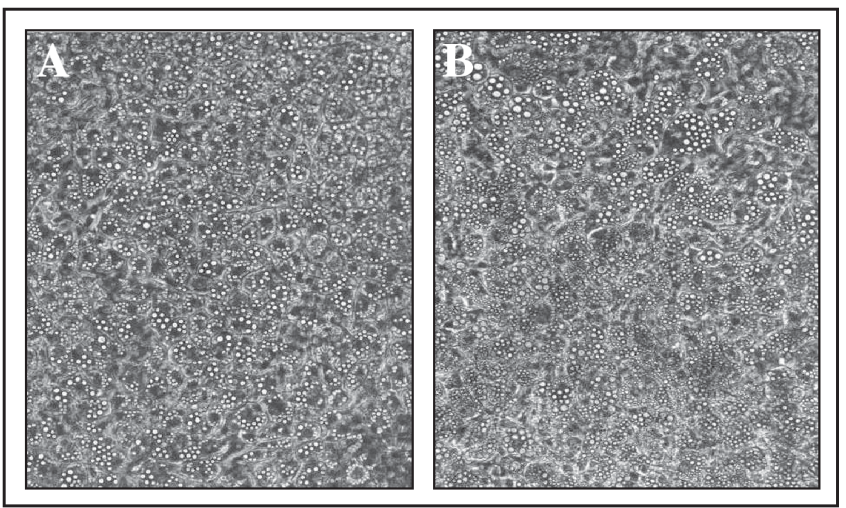

Clone 10 CMED

Clone 10 CMED + CB1954
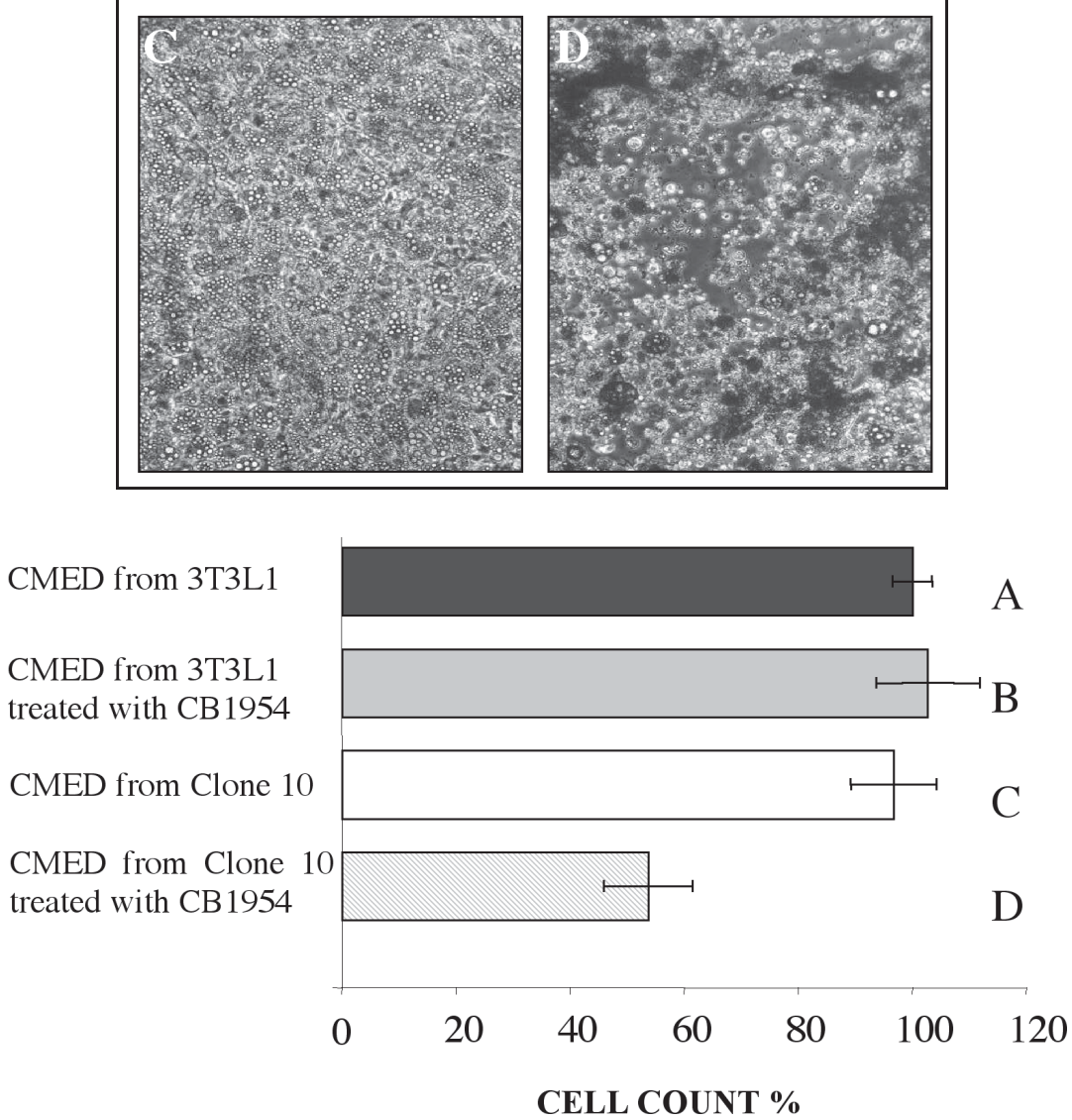

Figure 7. Bystander effect of NTR/CB1954 is mediated through a metabolite released to the medium.

Phase-contrast photomicrograph and cell number count of parental cells (3T3L1) grown with conditioned medium (CMED) derived from:

A) 3T3L1 untreated; B) 3T3L1 CB1954-treated; C) Transfected cells (clone 10) untreated; D) Transfected cells (clone 10) CB1954-treated. Cell death of parental cells was observed only when grown with CMED derived from transfected cells treated with the prodrug (D). No such effect was observed with any of the other conditions.

Each bar represents the mean \pm s.d. of triplicates. 
Expression assays showed that the transgene is activated and developmentally regulated within adipocytes in a qualitatively similar fashion to the endogenous aP2 gene. Since aP2 was originally isolated as a cDNA from differentiated adipocytes (Spiegelman et al., 1983 ) it was expected that the aP2 driven nitroreductase construct would be expressed only in differentiated cells. Figure 2B confirmed this observation, since no signal of nitroreductase could be observed in these cells prior to differentiation, thus indicating an appropriate developmental expression of the nitroreductase gene.

The addition of CB1954 into the culture medium killed all nitroreductase-expressing cells. On the other hand, parental cells were not affected by the prodrug and showed no signs of cytotoxicity until the concentration was increased to $2.5 \mathrm{mM}$. This is in agreement with other human and murine cells, where differential toxicity between NTR-expressing and non-expressing control cells has reached 10-100 fold (Bridgewater et al., 1995; Clark et al., 1997; Drabek et al., 1997). The degree of cytotoxicity correlated with the level of nitroreductase expression in transfected cells, presumably due to a more efficient conversion of the prodrug to the active metabolites. In the same way, low concentration of the prodrug rendered these cells more resistant to the killing, requiring longer time exposure to achieve a similar toxic effect (data not shown). One possible explanation for this effect is that at a lower concentration of the prodrug the cells are still capable of repairing the DNA adducts formed as result of the bioactivation but over certain concentration they are no longer capable of doing so.

The effects observed of the prodrug were gross changes in cell morphology with enlargement of the nuclei, cell shrinkage, membrane blebbing, and cell detachment, concomitant with a mechanism of cellular death by apoptosis. Both DNA fragmentation and Tunel assays confirmed the microscopic observations. TdTmediated dUTP nick end labelling (Tunel) showed specific staining indicative of apoptosis-mediated DNA strand breaks in cells expressing nitroreductase treated with the prodrug. Furthermore, DNA fragmentation and morphological data are also consistent with this observation, confirming the apoptosis-mediated cell death.

In gene therapy trials using the timidine kinase gene from herpes simplex virus (HSV-tk), it was shown that tumors regress even when only a fraction of the tumor mass contains the viral gene (Freeman et al., 1993). Furthermore, a few cells transfected with HSV-tk gene, without retroviral infectious capabilities, were also able to cause tumor regression (Ram et al., 1993). This implies that in the presence of ganciclovir, cells that produce HSV-tk are able to cause death of neighboring cells that do not themselves produce the enzyme. This phenomenon has been termed the 'bystander effect' (Kolberg R. 1992). Here it was shown that a bystander effect, similar to HSV $t k$ /ganciclovir is also observed with NTR/CB1954 system and this effect is presumably due to the presence of a toxic metabolite of the prodrug, which is released to the culture medium. A desirable feature of enzyme/prodrug combinations for applications in GDEPT is that the killing of modified cells results in the killing of adjacent unmodified cells. This bystander effect has been observed previously with NTR/CB1954 by some authors (Knox et al., 1988; Bridgewater et al., 1997 and Benouchan et al., 2003), although the same effect could not be observed by others (Clark et al., 1997). One possibility for this lack of bystander effect in some cells could be attributed to the intrinsic resistance to the prodrug or the lack of intimate cellular contact between nitroreductase-expressing and non-expressing cells.

Here, in vitro studies in 3T3L1 cells confirmed this bystander effect of CB1954 in adipocytes. We demonstrated that the effect is due to a toxic metabolite of CB1954 that is released in the culture medium confirming previous observations in murine fibroblasts (Bridgewater et al., 1997) and suggesting this as the cause of the extensive cell depletion we observed in a transgenic mouse model (Felmer et al., 2002). This active metabolite of CB1954 
may have important in vivo advantages for GEPT strategies, where the bystander effect would be increased in those tumors with few gap junctions (Bridgewater et al., 1997). At the same time, because cell contact would not be required, tumor models where tumor spread is restricted to a confined space could be more efficiently treated.

This bystander effect represents an important feature of any enzyme/prodrug system for potential applications in GDEPT, considering gene transfer to $100 \%$ of tumor cells in vivo is unlikely to be achieved. In the same way, this bystander effect would be especially useful in gene addition experiments, where the effects of variegated expression might silence the expression of the transgenes, thus enabling the killing of surrounding silenced cells. On the other hand, the lack of a bystander effect with NTR/CB1954, as observed in other studies, should also encourage the belief that ablation of specific cells in tissues such as pituitary, pancreas, CNS and immune system, which comprise more than one cell type in close association, can be accomplished with this approach. This would allow cell-lineage studies to unravel the developmental relationships between different cells in a tissue.

NTR/CB1954 system confirmed some of the advantages already highlighted in other mouse transgenic studies with respect to gene suicide systems. While conditional ablation with $t k$ gene is likely to be effective only in proliferating cells, considering that cell killing is mediated through inhibition of DNA synthesis (Borrelli et al., 1989), many potential target cell populations, such as non-cycling stem cells and terminally differentiated cell types, including adipocytes or neuron cells, are likely to be refractory to the toxic effects of the administered drug, despite significant expression of the herpes $t k$ gene. Furthermore, CB1954 can be readily administered in transgenic mice by intraperitoneal injection, whereas most ablation studies carried out with HSV $t k$ / ganciclovir have used minipumps. Diptheria toxin A, on the other hand, has the potential problem associated with its extreme cytotoxicity. Although this ensures that cells expressing low levels in a target cell population will be killed, it also means that any leakiness from transcriptional regulatory elements could lead to embryo lethality or deleterious effects when applied in an animal model. Such an effect would not be expected with NTR/CB 1954. Furthermore, it has been shown that CB1954 readily crosses the blood-brain barrier, thus making it feasible to target specific cell types within the central nervous system (Isles et al., 2001).

In conclusion, the described system should not only provide a good alternative approach for gene therapy studies, but it should also provide a new inducible approach to manipulating the number of cells in tissues of transgenic animals and the ability to study the recovery of the tissue from cell damage or loss.

\section{ACKNOWLEDGEMENTS}

The financial support of INIA, Chile (National Institute of Agricultural Research), and the Biotechnology and Biological Sciences Research Council UK, are gratefully acknowledged.

\section{REFERENCES}

BENOUCHAN M, DO NASCIMENTO F, SEBBAHLOURIKI M, SALZMANN JL, CREPIN M, PERRET GY, COLOMBO BM (2003) Bystander cell killing spreading from endothelial to tumor cells in a threedimensional multicellular nodule model after Escherichia coli nitroreductase gene delivery. Biochem Biophys Res Commun. 311: 822-8

BORRELLI E, HEYMAN RA, ARIAS C, SAWCHENKO PE, EVANS RM (1989) Transgenic mice with inducible dwarfism. Nature 339 (6225): 538-41

BORTNER, C OLDENBURG, N CIDLOWSKI, J (1995) The role of DNA fragmentation in apoptosis. Trends Cell Biol 5: 21-26

BREITMAN ML, CLAPOFF S, ROSSANT J, TSUI LC, GLODE LM, MAXWELL IH, BERNSTEIN A (1987) Genetic ablation: targeted expression of a toxin gene causes microphthalmia in transgenic mice. Sci 238(4833): 1563-5

BRIDGEWATER JA, SPRINGER CJ, KNOX RJ, MINTON NP, MICHAEL NP, COLLINS MK (1995) Expression of the bacterial nitroreductase enzyme in mammalian cells renders them selectively sensitive to killing by the prodrug CB1954. Eur J Cancer 14: 2362-70

BRIDGEWATER JA, KNOX RJ, PITTS JD, COLLINS MK, SPRINGER CJ (1997) The bystander effect of the 
nitroreductase/CB1954 enzyme/prodrug system is due to a cell-permeable metabolite. Hum Gene Ther 10: 709-17

CAMPER SA, SAUNDERS TL, KENDALL SK, KERI RA, SEASHOLTZ AF, GORDON DF, BIRKMEIER TS, KEEGAN CE, KAROLYI IJ, ROLLER ML (1995) Implementing transgenic and embryonic stem cell technology to study gene expression, cell-cell interactions and gene function. Biol Reprod 52: 246-57

CLARK AJ, IWOBI M, CUI W, CROMPTON M, HAROLD G, HOBBS S, KAMALATI T, KNOX R, NEIL C, YULL F, GUSTERSON B (1997) Selective cell ablation in transgenic mice expression $E$. coli nitroreductase. Gene Ther 4: 101-10

COOK J, LUCA J, SIBLEY E, BOLANOWSKI M, CHRISTY R, KELLY T, LANE D (1988) Expression of the differentiation induced gene for fatty acidbinding protein is activated by glucocorticoids and cAMP. Proc Natl Acad Sci 85: 2949-2953

DRABEK D, GUY J, CRAIG R, GROSVELD F (1997) The expression of bacterial nitroreductase in transgenic mice results in specific cell killing by the prodrug CB1954. Gene Ther Feb 4(2): 93-100

EVANS GA (1989) Dissecting mouse development with toxigenics. Genes Dev 3: 259-63

FELMER R, CUI W, CLARK A.J (2002) Inducible ablation of adipocytes in adult transgenic mice expressing the E. coli nitroreductase gene. J Endocrinol 175: 487-98

FREEMAN SM, ABBOUD CN, WHARTENBY KA, PACKMAN CH, KOEPLIN DS, MOOLTEN FL, ABRAHAM GN (1993) The 'bystander effect': tumor regression when a fraction of the tumor mass is genetically modified. Cancer Res 21: 5274-83

FRIEDLOS F, QUINN J, KNOX RJ, ROBERTS JJ (1992) The properties of total adducts and interstrand crosslinks in the DNA of cells treated with CB 1954. Exceptional frequency and stability of the crosslink. Biochem Pharmacol 6: 1249-54

GALLAGHER E, LODGE P, ANSELL R, MCWHIR J (2003) Isolation of murine embryonic stem and embryonic germ cells by selective ablation. Transgenic Res 4: 451-60

ISLES AR, MA D, MILSOM C, SKYNNER MJ, CUI W, CLARK AJ, KEVERNE EB, ALLEN ND (2001) Conditional ablation of neurons in transgenic mice. $\mathrm{J}$ Neurobiol 3: 183-193

IZQUIERDO M, MARTIN V, DE FELIPE P, IZQUIERDO JM, PÉREZ-HIGUERAS A, CORTÉS ML, PAZ JF, ISLA A, BLÁZQUEZ MG (1996) Human malignant brain tumor response to herpes simplex thymidine kinase (HSVtk)/ganciclovir gene therapy. Gene Ther 3: 491-5

KNOX RJ, FRIEDLOS F, JARMAN M, ROBERTS JJ (1988) A new cytotoxic, DNA interstrand crosslinking agent, 5-(aziridin-1-yl)-4-hydroxylamino-2nitrobenzamide, is formed from 5-(aziridin-1-yl)-2,4dinitrobenzamide (CB 1954) by a nitroreductase enzyme in Walker carcinoma cells. Biochem Pharmacol 24: 4661-9

KNOX RJ, FRIEDLOS F, BOLAND MP (1993) The bioactivation of CB 1954 and its use as a prodrug in antibody-directed enzyme prodrug therapy (ADEPT). Cancer Metastasis Rev 2: 195-212

KOLBERG R (1992). Animal models point the way to human clinical trials. Sci 256: 772-783

MOOLTEN FL, WELLS JM, HEYMAN RA, EVANS RM (1990) Lymphoma regression induced by ganciclovir in mice bearing a herpes thymidine kinase transgene. Hum Gene Ther 1(2): 125-34

PALMITER RD, BEHRINGER RR, QUAIFE CJ, MAXWELL F, MAXWELL IH, BRINSTER RL (1987) Cell lineage ablation in transgenic mice by cell-specific expression of a toxin gene. Cell 3: 435-43

RAM Z, CULVER KW, WALBRIDGE S, BLAESE RM, OLDFIELD EH (1993) In situ retroviral-mediated gene transfer for the treatment of brain tumors in rats. Cancer Res 1: 83-8

ROSS SR, GRAVES RA, GREENSTEIN A, PLATT KA, SHYU HL, MELLOVITZ B, SPIEGELMAN BM (1990) A fat-specific enhancer is the primary determinant of gene expression for adipocyte P2 in vivo. Proc Natl Acad Sci USA 24: 9590-4

SELLINS K, COHEN J (1987) Gene induction by girradiation leads to DNA fragmentation in lymphocytes. J Immunol 10: 3199-206

SPIEGELMAN BM, FRANK M, GREEN H (1983) Molecular cloning of mRNA from 3T3 adipocytes. Regulation of mRNA content for glycerophosphate dehydrogenase and other differentiation-dependent proteins during adipocyte development. J Biol Chem 16: $10083-9$

SPRINGER CJ, NICULESCU-DUVAZ I (2000) Approaches to gene-directed enzyme prodrug therapy (GDEPT). Adv Exp Med Biol: 465: 403-9

STUDENT AK, HSU RY, LANE MD (1980) Induction of fatty acid synthetase synthesis in differentiating 3T3L1 preadipocytes. J Biol Chem 10: 4745-50

WALLACE H, LEDENT C, VASSART G, BISHOP JO, AL-SHAWI R (1991) Specific ablation of thyroid follicle cells in adult transgenic mice. Endocrinol 6: 3217-26 